\title{
The impact of IL-6 and IL-28B gene polymorphisms on treatment outcome of chronic hepatitis $C$ infection among intravenous drug users in Croatia
} \author{
Forempoher $^{3}$, Ozren Polašek ${ }^{6}$, Janoš Terzić ${ }^{2}$, Šimun Anđelinović ${ }^{3}$ \\ ${ }^{1}$ Department of Internal Medicine, Division of Gastroenterology, Clinical Hospital Split, Split, Croatia \\ 2 Department of Immunology, Univeristy of Split, School of Medicine, Split, Croatia \\ 3 Department of Pathology, Clinical Hospital Split, Split, Croatia \\ 4 Department of Research in Biomedicine and Health, Univeristy of Split, School of Medicine, Split, Croatia \\ 5 Department of Infectious Diseases, Clinical Hospital Split, Split, Croatia \\ 6 Department of Public Health, Univeristy of Split, School of Medicine, Split, Croatia \\ Corresponding Author: Zoran Bogdanović \\ Email address: suzbog@gmail.com
}

Zoran Bogdanović corresp.. ${ }^{1}$ ， Ivana Marinović-Terzić ${ }^{2}$, Sendi Kuret ${ }^{3}$ ， Ana Jerončić ${ }^{4}$ ， Nikola Bradarić ${ }^{5}$, Gea

Background. Several genes and their single nucleotide polymorphisms are associated with either spontaneous resolution of hepatitis $C$ infection or better treatment-induced viral clearance. We tested a cohort of intravenous drug users (IVDU) diagnosed with chronic hepatitis $\mathrm{C}(\mathrm{HCV})$ for treatment response and its association with the single nucleotide polymorphisms in the Interleukin-6 (rs1800795-IL6) and the Interleukin-28B (rs12979860-IL28B) genes. Methods. The study included 110 Croatian IVDU positive for anti-HCV antibody. Genotyping was performed by PCR based approach. Patients were treated by standard pegylated-interferon/ribavirin and followed throughout a period of four years, during which sustained virological response (SVR) was determined. All data were analysed with statistical package SPSS 19.0 (IBM Corp, Armonk, NY) and PLINK v1.07 software. Results. Patients showed a significantly better response to treatment according to the number of copies of the $C$ allele carried at rs1800795-IL6 $(P=0.034)$. All but one of the patients with CC genotype achieved SVR (93\%), whereas the response rate of patients with GG genotype was $64 \%$. The association of rs1800795-IL6 with SVR status remained significant after further adjustment for patients' age, fibrosis staging, and viral genotype (OR 2.15, 95\% Cl 1.16-4.68, $\mathrm{P}=0.019$ ). Distributions of allele frequencies at the locus rs12979860-IL28B among the study cohort and the underlying general population were suggestive of a protective effect of CC genotype in acquiring chronic hepatitis $\mathrm{C}$ in the Croatian IVDU population. Discussion. The rs1800795-IL6 polymorphism is associated with positive response to treatment in IVDU patients positive for HCV infection. A protective role of rs12979860-IL28B CC genotype in acquiring chronic hepatitis C is 
suggested for Croatian IVDU population. 
2 The impact of IL-6 and IL-28B gene polymorphisms on treatment outcome of chronic hepatitis $\mathrm{C}$ infection among intravenous drug users in Croatia

6 Zoran Bogdanović, ${ }^{1 *}$ Ivana Marinović-Terzić, ${ }^{2 *}$ Sendi Kuret, ${ }^{3 *}$ Ana Jerončić, ${ }^{4 *}$ Nikola Bradarić, ${ }^{5}$

7 Gea Forempoher, ${ }^{3}$ Ozren Polašek, ${ }^{6}$ Janoš Terzić, ${ }^{2}$ and Šimun Anđelinović ${ }^{3}$

$8 *$ These authors contributed equally

11 Clinical Hospital Split, Departments of: Internal Medicine, Division of Gastroenterology ${ }^{1}$, 12 Pathology ${ }^{3}$, and Infectious diseases ${ }^{5}$; and University of Split School of Medicine, Departments 13 of: Immunology ${ }^{2}$, Research in Biomedicine and Health ${ }^{4}$, and Public Health ${ }^{6}$, Split 21000 , 14 Croatia.

16 Corresponding author: Zoran Bogdanović, University of Split, School of Medicine Department 17 of Internal Medicine, Division of Gastroenterology, Spinciceva 1, Split 21000, Croatia; 18 suzbog@gmail.com ; fax: + 38521435820, phone: +38521453825

21 Short title: IL genotypes and hepatitis C outcome 


\section{ABSTRACT}

27 Background. Several genes and their single nucleotide polymorphisms are associated with either spontaneous resolution of hepatitis $\mathrm{C}$ infection or better treatment induced viral clearance. We tested a cohort of intravenous drug users (IVDU) diagnosed with chronic hepatitis $\mathrm{C}(\mathrm{HCV})$ for treatment response and its association with single nucleotide polymorphisms in Interleukin-6 (rs1800795-IL6) and Interleukin-28B (rs12979860-IL28B) genes.

Methods. The study included 110 Croatian IVDU positive for anti-HCV antibody. Genotyping was performed by PCR based approach. Patients were treated by standard pegylatedinterferon/ribavirin and followed throughout a period of four years, during which sustained virological response (SVR) was determined. All data were analysed with statistical package SPSS 19.0 (IBM Corp, Armonk, NY) and PLINK v1.07 software.

37 Results. Patients showed a significantly better response to treatment according to the number of copies of the $\mathrm{C}$ allele carried at rs1800795-IL6 $(\mathrm{P}=0.034)$. All but one of the patients with CC genotype achieved SVR (93\%), whereas the response rate of patients with GG genotype was 64\%. The association of rs1800795-IL6 with SVR status remained significant after further 41 adjustment for patients' age, fibrosis staging, and viral genotype (OR 2.15, 95\%CI 1.16-4.68, $\mathrm{P}=0.019$ ). Distributions of allele frequencies at the locus rs12979860-IL28B among the study

43 cohort and the underlying general population were suggestive of a protective effect of $\mathrm{CC}$ 44 genotype in acquiring chronic hepatitis $\mathrm{C}$ in the Croatian IVDU population. 
45 Discussion. The rs1800795-IL6 polymorphism is associated with positive response to treatment

46 in IVDU patients positive for $\mathrm{HCV}$ infection. A protective role of rs12979860-IL28B CC

47 genotype in acquiring chronic hepatitis $\mathrm{C}$ is suggested for Croatian IVDU population.

\section{INTRODUCTION}

51 It is estimated that chronic hepatitis $\mathrm{C}$ virus (HCV) infection affects nearly 170 million

52 individuals worldwide (Averhoff et al. 2012; WHO 2014). It poses as one of the most important

53 and growing threats to public health. Being an intravenous drug user (IVDU) is one of the most

54 important risk factors in acquiring this infection.

55 Only a minority of patients are able to clear the virus, and so do not run the risk of 56 developing HCV induced end liver damage. Majority of patients will develop either acute or 57 chronic hepatitis that will require a treatment. PegIFN- $\alpha 2 a$ in combination with ribavirin was used as a standard treatment in patient that did not meet exclusion criteria. Since 2011 , a few generations of direct-acting antivirals (DAAs) were approved for HCV treatment (Zeuzem et al.

60 2011). Each of three DAAs subgroups can be used as a component of a triple combination 61 regimen with PegIFN-a and ribavirin, yielding SVR rates of 60-100\%. Response rate depends

62 on the DAA used, the HCV genotype, the presence of detectable pre-existing amino acid 63 substitutions conferring resistance to the DAA used and the severity of liver disease (European 64 Association for the Study of the Liver 2014). With three new HCV DAAs approved, IFN-free 65 combinations are reserved for patients with advanced liver disease (fibrosis METAVIR score F3 66 or F4). 
Among the different and diverse list of factors that influence the therapeutic response, the

68 host's cytokines play a very important role. The cytokine levels are directly influenced by certain

69 gene polymorphisms located within their coding or regulatory regions (Wilson et al. 1997).

70 Among others, IL-6 is reported to be elevated in chronic HCV infection compared to

71 healthy controls (Malaguarnera et al. 1997). The low-producing Interleukin 6 genotype IL-6 CC

72 (IL-6 rs1800795 G174C) was associated with spontaneous clearance of HCV in patients infected

73 by contaminated blood products (Barrett et al. 2001). On contrary, high producing Interleukin 6

74 genotypes of the rs 1800795 174G/C polymorphism (i.e., GG or GC genotypes) were associated

75 with a greater likelihood of SVR in patients coinfected with HCV and HIV (Nattermann et al.

76 2007).

77 Human Interleukin-28B gene encodes interferon lambda-3 (IFN-lambda-3). Interferon

78 lambda has demonstrated antiviral activity against HCV genotype 1 in vivo (Pagliaccetti \&

79 Robek 2010) and in vitro (Muir et al. 2010). It has been shown that a single nucleotide

80 polymorphism (SNP) of IL28B gene (IL-28B rs12979860 C/T) predicts hepatitis C treatment

81 induced viral clearance (Ge et al. 2009; Halfon et al. 2011; Lin et al. 2011; Lindh et al. 2011;

82 Luo et al. 2013) and is associated with spontaneous resolution of hepatitis C infection (Duggal et

83 al. 2013; Kurbanov et al. 2011; Shi et al. 2012; Thomas et al. 2009; Tillmann et al. 2010).

84 Here, we studied whether interleukin-28B or interleukin-6 (IL-6) promoter SNP affects the

85 response to the PegIFN- $\alpha 2 \mathrm{a} /$ ribavirin antiviral treatment in IVDU patients diagnosed with

86 chronic hepatitis C. We determined IL-6 promoter and IL-28B gene polymorphisms in a cohort

87 of 110 patients with chronic hepatitis C. All IVDU positive patients diagnosed with chronic

88 hepatitis $\mathrm{C}$ were treated with a standard protocol of peg-interferon alpha-2a and ribavirin. Rates 
89 of SVR were compared between IL-6 and IL-28B wild type, heterozygous and homozygous

90 genotypes.

91

92

93

94

95

96

SUBJECTS \& METHODS

97

98

\section{The study samples}

99

The sample of 112 patients was recruited from the outpatient hepatology unit at the Split Medical

100 Center, Croatia and was followed from September 2007 until November 2013. The sample was

101 drawn from the total of $947 \mathrm{HCV}$ positive patients but only 112 individuals were diagnosed, 102 biopsied, genotyped, treated and followed for a period of four years. Two patients were excluded

103 from further analysis due to an ambiguous SVR status, possible reuse of intravenous drugs and 104 re-infection with a different viral strain, resulting in a cohort of 110 patients. All enrolled 105 patients had an alcohol consumption of less than 14 units per week and other common forms of 106 chronic liver disease were excluded in all cases. Patients were Caucasians with the median (IQR) 107 age at diagnosis of 40 (35-45) years in the SVR group and 41.5 (39-47) in the non-responder 108 (NR) group.

109 We also used the data from the 10,001 Dalmatians biobank as the source of population110 based sample of the underlying, general Croatian population. All controls were apparently 
111 healthy subjects with no record of addiction, risky behaviors or detected HCV infection (Polasek

112 2013; Rudan et al. 2009).

113 Patients' data were collected as a part of standard clinical procedure and the informed

114 consent was obtained prior to participating in the study in all cases. The Ethics Committee of the

115 Clinical Hospital Split approved the study (No: 2181-147-06-01/01-M.J).

116

117 Diagnosis and treatment of HCV infection

118

119 A third generation enzyme immunoassay (ELISA; Abbott Diagnostics, Germany) was used to

120 test all subjects for HCV specific antibodies. Reverse-transcriptase polymerase chain reaction

121 (RT-PCR) assay (Amplicor; Roche Diagnostic Systems, New Jersey, USA) was used to test for

122 HCV RNA in all subjects, in order to determine SVR. PegIFN- $\alpha$ was used as a subcutaneous

123 injection of $180 \mu \mathrm{g}$ (or less if dose reduction was needed), once a week. Depending on patient's

124 body weight $(\leq 75 \geq \mathrm{kg}$ ), a total of 1000 or $1200 \mathrm{mg}$ of ribavirin was administered, in divided 125 doses.

126 A sustained viral response (SVR) was defined as undetectable HCV RNA 12 weeks or 24

127 weeks after treatment completion as assessed by a sensitive molecular method with a lower level

128 of detection $15 \mathrm{IU} / \mathrm{ml}$. Non responders (NR) were patient who did not meet the SVR.

129 Our patients were followed up for four years and we were able to identify relapses. Patients that

130 relapsed during the follow up time were included in non-responder group.

\section{Liver Histology}


132 Percutaneous liver biopsy was performed at the time of initial diagnosis and at the beginning of

133 the treatment, using the Trucut biopsy technique (Sterylab, Italy) following informed consent.

134 Inflammation was graded using a histological activity index (HAI) (Knodell et al. 1981) and

135 fibrosis (Ishak et al. 1995). Every fifth biopsy was independently validated by two pathologists.

136 A minority of patients was not biopsied either due to secondary coagulopathy or refusal to sign

137 the informed consent and to participate in the procedure.

138

\section{DNA extraction}

140 A salting out technique was used to extract DNA from whole blood or using the QIAmp DNA

141 midi prep kit, (Qiagen Ltd., Crawley, UK). The obtained DNA was used for IL-6 promoter and

142 IL-28B genotyping. During this process, all the RNA was removed by incubating the digested 143 preparation with $1.5 \mathrm{ml}$ ribonuclease A (Boehringer Mannheim UK Ltd, East Sussex, UK) per $144400 \mathrm{ml}$ of nuclear lysate.

\section{IL-6 and IL28B genotyping}

148 A 175 base pair (bp) fragment of the human IL-6 gene spanning the promoter IL-6 G-174C 149 region was amplified with gene specific primers (Roche Diagnostics, Alameda, California, 150 USA). The resulting PCR fragments were analyzed with hybridization probes labeled with 151 LightCycler Red 640. The genotypes were identified by running a melting curve with specific 152 melting points (Tm) (Tib Molbiol GmbH, Berlin, Germany).

153 Genetic polymorphism in a SNP located near the IL-28B gene (rs12979860) was

154 determined by enzymatic digestion of the PCR product. DNA fragments were amplified by using 
155 specific primers. Primer sequences were 5'-GCCTGTCGTGTACTGAACCA-3', and 5'-

156 GCTCAGGGGTCAAATCACAGAAG-3', a PCR product of $143 \mathrm{bp}$ was digested with HhaI

157 enzyme and the resulting fragments of $27,38,65$ and 78 bp were separated on $20 \%$ acrylamide

158 gel followed by silver staining (Figure 1).

160 Statistical analysis

161 Data were analysed with the statistical package SPSS 19.0 (IBM Corp, Armonk, NY) and

162 PLINK v1.07 software (Purcell et al. 2007). Absolute numbers and percentages were used to

163 describe categorical data, whereas median and interquartile ranges (IQR) were used to describe

164 quantitative data. One sample binomial test was used to assess distributions of sex, and response

165 to the treatment. The association of response-to-treatment with sex or the viral genotype in

166 infected patients was estimated with the Pearson's chi square test. Furthermore, nonparametric

167 Mann-Whitney test was used to assess age differences, or differences in severity of fibrosis

168 between the response groups.

169 Genetic association tests were mostly performed within PLINK software by using the

170 case and control design. We defined cases as the group of patients that achieved SVR. Full

171 model association tests were run in PLINK for each SNP using either chi-square or, when

172 appropriate, Fisher exact test; and the best-fit model was identified. Full model included basic

173 allelic, Cochran-Armitage trend, genotypic, dominant gene action and the recessive gene action

174 tests. Additionally, the difference in distribution of IL28B CC carriers vs CT+TT carriers across

175 the response groups was estimated by the Pearson's chi square test using the SPSS v19 software

176 (IBM, Armonk, NY) since the recessive model in PLINK tests only the minor allele and in both

177 our samples (patients and the underlying, healthy general population) the allele C at the IL28B 
178 locus was the dominant allele. All significant p-values yielded by genetic tests were further

179 controlled by empirical p-values which were generated by the permutation procedure. Cochran-

180 Mantel-Haenszel statistics was used to test whether the predictive power of the SNP markers was

181 independent of viral genotypes detected in infected patients. Associations of the SVR status with

182 both SNPs were further evaluated by multivariate logistic regression while accounting for

183 covariates/factors: age, viral genotype, stage of fibrosis.

184 The achieved post hoc power for genetic association tests was calculated with Genetic

185 Power Calculation software (http://pngu.mgh.harvard.edu/ purcell/gpc/), whereas G*power

186 version 3.1.7 (Universität Kiel, Germany) was used to assess the achieved power for comparison

187 of genotype frequencies between the two population samples.

188

189 RESULTS

190

191 A total of 110 IVDU patients with elevated liver function tests were diagnosed with a chronic

192 hepatitis C, treated by standard interferon 2-alfa/ribavirin protocol and followed over at least one

193 year for a SVR. The majority of treated patients (78 out of 110 , or $71 \%$ ) achieved SVR (one

194 sample binomial test, $\mathrm{P}<0.001$ ). Men were significantly more prevalent in our sample than

195 women: $82(75 \%)$ vs. 28 (25\%) (one sample binomial test, $\mathrm{P}<0.001)$. Demographic and clinical

196 characteristics of the sample are presented in Table 1. As shown in Table 1, non-responders were

197 significantly older than responders. We found no association of the SVR status with the sex, the 198 initial Ishak score fibrosis stage, or the viral genotype.

199 Distributions of patients' genotypes across response-to-treatment groups are shown for

200 both SNP loci, rs1800795- IL6 and rs12979860- IL28B, in Table 2. 
With regard to genetic variation at the rs1800795-IL6 locus, we determined Hardy-

202 Weinberg equilibrium in both response groups (exact test, p-values from 0.392 to 0.819 ).

203 Overall, the genetic association tests indicated that the addition of allele ' $\mathrm{C}$ ' has protective effect

204 and increases the chance of achieving SVR. Specifically, several genetic association tests

205 confirmed the association between rs1800795-IL6 polymorphism and SVR status, with the

206 Cochran-Armitage trend test providing the best model fit $(\mathrm{chi}=4.477, \mathrm{df}=1, \mathrm{p}=0.034$, empirical

$207 \mathrm{p}=0.039)$. Patients with rs1800795-IL6 CC genotype had significantly better SVR (14 out of 15, $20893 \%$ ) compared to those with GC (37 out of 52, 71\%) or GG (27 out of 43, 63\%) genotypes

209 (Figure 2). The achieved post-hoc power of this association test was high: 90\% (calculated under

210 the additive model, at type I error rate of 0.05 and with responders/non-responders ratio of $21178 / 32)$

212 After controlling for viral genotypes, the association of rs1800795-IL6 polymorphism

213 with SVR status remained significant (Mantel-Haenszel $2 \times 2$ chi $^{2}=4.483, p=0.034$, with odds

214 ratio of $1.99,95 \%$ CI 1.05-3.78). The association was further evaluated by multivariate logistic

215 regression analysis while accounting for covariates: age, viral genotype, and fibrosis ( $\mathrm{F} \geq 3)$. The

216 result of regression analysis confirmed that the addition of allele ' $\mathrm{C}$ ' increased the chance of

217 achieving SVR (OR 2.45, 95\% CI 1.13-5.30, $\mathrm{P}=0.023$ ). Besides the rs1800795-IL6

218 polymorphism, age was the only covariate that significantly affected SVR status, with each

219 additional year slightly decreasing the chance of SVR response (significance at the level of 0.1, 220 OR 0.95, 95\%CI 0.89-1.01, $\mathrm{P}=0.096)$.

221 The genotype frequencies at the rs12979860-IL28B locus met the Hardy-Weinberg 222 expectations in nonresponders (exact test, $\mathrm{p}=0.473$ ), and deviated from the Hardy-Weinberg 223 equilibrium in SVR cases (i.e. SVR responders, $\mathrm{p}=0.004$ ). When we analysed the genotype 
224 frequencies at the rs12979860 locus in the IVDU cohort, and in the underlying, apparently

225 healthy, general-population sample ( $\mathrm{n}=531$ individuals; HWE, $\mathrm{p}=0.999)$, we observed that the

226 frequencies of CC, CT and TT genotypes in our cohort were: $27 \%, 63 \%$, and $10 \%$; whereas the

227 corresponding frequencies in the population-based sample were $49 \%, 42 \%$, and $9 \%$ (Figure 3).

228 The finding demonstrated a large and significant reduction of CC genotype (z-score test for

229 proportions, $\mathrm{p}<0.001$ ), and a significant increase in frequency of heterozygous $\mathrm{TC}$ genotype

230 ( $\mathrm{p}<0.001)$ in the IVDU cohort of chronic HCV patients compared to the underlying, apparently

231 healthy population. The frequencies of TT genotype were comparable between the groups

$232(\mathrm{p}=0.741)$. The post hoc power for detecting medium size effect in genotype frequencies between

233 these two population samples was $99 \%$.

234 With regard to the SVR responder and non-responder groups, we did not, however, 235 observe a significant association of SVR response with the allele-carrier groups: CC and CT+TT 236 (chi square $=0.118, \mathrm{df}=1, \mathrm{p}=0.732$ ); although the frequency of $\mathrm{CC}$ genotype was in fact somewhat 237 higher in responders (by 3\%). The result persisted after we controlled for viral genotypes 238 (Mantel-Haenszel $2 \times 2$ chi2 $=0.630, \mathrm{p}=0.427$ ) and after multivariate logistic regression using age, 239 viral genotype and fibrosis stage as additional predictors. It should be noted, however, that the 240 achieved power for this test, under the dominant genetic model: CT+TT vs CC, type I error rate 241 of 0.05 , and observed responders/non-responders ratio was very low: $9 \%$. This was in contrast to 242 a priori power calculation that was based on Ge's data (Ge et al. 2009) which showed that in 243 treatment-naive, chronic HCV type 1 patients of European-American origin, as little as 20 244 patients were enough to achieve $80 \%$ of power for the rs 12979860 -IL28B association test on the 245 response to therapy. Also, the observed penetrance of non-responder phenotype in our cohort of 
$24629 \%$ was considerably lower than the penetrance in Ge's cohort of $45 \%$ (z-score test for

247 proportions, $\mathrm{P}=0.001$; achieved power $80 \%$ ).

248

249 DISCUSSION

250

251 This study investigated the role of IL-6 and IL-28B gene polymorphisms on SVR in IVDU

252 patients diagnosed with chronic hepatitis $\mathrm{C}$ infection. The treatment was conventional and 253 included Peg IFN combined with ribavirin for either 48 weeks (genotype 1) or 24 weeks

254 (genotype 3). We defined sustained virological response as an absence of detectable virus at the 255 end of follow up evaluation and or disease relapses according to the standard definitions (Ghany 256 et al. 2009).

Interleukin-6 was originally discovered as a protein that caused the final differentiation of 258

B cells into immunoglobulin secreting cells (Muraguchi et al. 1988). Additional work showed 259 that IL-6 and its receptor - sIL-6R $\alpha$ suppress neutrophil recruitment at site of acute inflammation, making way for the influx of monocytes as the inflammatory response is sustained (Kopf et al. 261 1994). IL-6 is well known pro-inflammatory cytokine with pro-tumorigenic potential

262 (Grivennikov et al. 2009) and is emerging as a key regulatory signal in the development of the 263 newly described pro-inflammatory effectors T-cell subset, so called Th17 cells (Harrington et al. 264 2005). The IL-6 rs1800795 G allele has been also associated with higher degrees of liver 265 necroinflammation (Falleti et al. 2010) and fibrosis (Cussigh et al. 2011).

266 In our study, allele C at rs1800795-IL6 - a SNP in the IL-6 gene promoter, was associated

267 with sustained virological response (OR 2.45, 95\%CI 1.13-5.30, $\mathrm{P}=0.023$ ). The genotype that 268 confers the highest degree of protection in terms of achieving SVR, rs1800795-IL6 CC, 
269 demonstrated an overwhelming lower relapse rate in HCV treated patients ( 1 out of 15 patients, $2707 \%$ ). Similar results were reported for Italian non-IVDU HCV infected patients thus 271 corroborating the importance of our findings (Cussigh et al. 2011). According to prior studies, 272 the CC genotype appears to be associated with significantly lower level of plasma IL-6, whereas 273 the GG and GC genotypes appear to have higher levels of plasma IL-6 (Fishman et al. 1998; 274 Lapinski 2001). This implies a possible connection of IL-6 status with the therapy outcome. The 275 putative low producing IL-6 phenotype may play a protective role against chronic hepatitis C 276 infection by helping to clear the viral particles during standard therapy. Chronic hepatitis C 277 patients with rs1800795-IL6 CC genotype and lower IL-6 serum level may have an attenuated 278 adoptive immune response, directed away from damaging, pro-inflammatory and autoimmune to 279 predominately suppressive and anti-viral inflammatory response.

An IL-28B gene single nucleotide polymorphism is located $8 \mathrm{~kb}$ upstream of the start 281 codon of IL-28B gene that encodes interferon lambda (IFN- $\lambda$ ) a member of type III IFN family. 282 IFN- $\lambda$ interacts with a transmembrane receptor to induce a potent antiviral response (Donnelly \& 283 Kotenko 2010; Fox et al. 2009; Li \& Huang 2007). The antiviral activity is mediated through the 284 activation of the either JAK-STAT (IFN $\alpha, \lambda$ and $\gamma$ ) or MAPK (IFN $\alpha$ and $\lambda$ ) pathways (Arslani 285 et al. 2013). There is a strong association of genetic variations in IL-28B gene with response to 286 therapy (Ge et al. 2009; Suppiah et al. 2009; Tanaka et al. 2009), and with spontaneous HCV 287 clearance (Duggal et al. 2013). In our cohort of IVDU patients diagnosed with chronic hepatitis 288 C no association between the therapy outcome and the single nucleotide polymorphism in the IL289 28B gene, rs12979860-IL28B was identified, but the study was largely underpowered to draw 290 the solid conclusion from this test. Nevertheless, our data still do support involvement of the 
291 rs12979860-IL28B CC genotype in both of these patho-physiological/immunological processes:

292 spontaneous HCV clearance and the response to therapy.

293 Firstly, when we compared our cohort of IVDU patients suffering from chronic HCV

294 with the population-based sample taken from the apparently healthy, underlying population; the

295 frequency of the favorable rs12979860-IL28B CC genotype which has been also associated with

296 the spontaneous clearance of $\mathrm{HCV}$, was largely decreased in the patient group. Conversely, the

297 frequencies of genotypes considered to have a neutral effect on acquiring HCV

298 infection/response to therapy were either increased in patients (TC) or showed no difference

299 between the samples (TT). In other words, the protective genotype rs12979860-IL28B CC was

300 found at much lower frequency in infected IVDU individuals with chronic HCV (27\%) than in

301 the underlying, healthy population (49\%), thus strongly pointing towards the selective loss of CC

302 homozygotes in the patient population.

303 In line with our finding, Gelinas et al. have observed significantly higher prevalence of

304 the responder genotype rs $12979860 \mathrm{CC}$ in a group of IVDU who were spontaneous resolvers

305 from a HCV infection than in a baseline population of IVDU users (Gelinas et al. 2013);

306 suggesting a dilution of CC genotype in chronic IVDU HCV patients. Additionally, also

307 supporting our findings, Ezzikouri et al. found that patients who had cleared HCV spontaneously

308 were from 2.7 to 4.7 times more likely to carry CC genotype than the TC, or the TT genotype,

309 respectively (Ezzikouri et al. 2013) while Montes-Cano et al. observed the CC genotype in 73\%

310 of individuals with spontaneous resolution of $\mathrm{HCV}$ infection versus only $46 \%$ in individuals with

311 the persistent infection (Montes-Cano et al. 2010).

312 Secondly, our results still suggest the positive effect of rs12979860-IL28B CC genotype

313 in acquiring SVR. In particular, the distribution of rs12979860-IL28B genotypes in the cohort of 
314 IVDU chronic patients significantly deviated from HWE-P only in the group of responders,

315 whereas in non-responders, and in healthy controls the rs12979860-IL28B genotypes followed

316 the HWE. Since the case (SVR responder) genotypes will only be in HWE under the

317 multiplicative genetic model (Lewis \& Knight 2012), the departure from this equilibrium, if

318 found exclusively in cases, can be expected in relatively small samples of patients over a range

319 of genetic models and is indicative of the actual association to the trait under study (Wittke-

320 Thompson et al. 2005). In addition, we have observed somewhat higher percentage of CC

321 genotype in SVR cases, although this percentage did not reach a statistical significance.

322 Similar to our results, Searberg et al. also did not found the association between

323 rs 12979860-IL28B genotypes and the spontaneous clearance of HCV in men who have sex with

324 men (Seaberg et al. 2015). There are obviously a large number of factors: demographic, viral,

325 and human genetic factors; which influence HCV viremia and the results on distribution of

326 particular SNPs should be interpreted in a larger context. The fact that the frequency of

327 rs12979860 CC genotype varies in different ethnic groups or geographical areas adds to this

328 complexity. In particular, several studies have estimated that East Asians had a high percentage

329 of CC genotype, whereas the frequency of this genotype was intermediate in Europeans and

330 minor frequency in African cohorts (Ge et al. 2009; Thomas et al. 2009).

331 Concerning the geographic variability of rs12979860 CC genotypes, previous studies on

332 Caucasian patients who were infected with the $\mathrm{HCV}$ viral genotype 1 estimated the prevalence of

333 CC genotypes to be between 35\% and 39\% (Cavalcante et al. 2012; Ge et al. 2009; Montes-Cano

334 et al. 2010; Nattermann et al. 2011). The percentage of CC genotypes observed in our patients

335 infected with the same viral genotype was $27 \%$ (95\% CI $19-36 \%)$ which is somewhat lower,

336 suggesting that the impact of IL-28B polymorphism on acquiring of infection or spontaneous 
337 clearance of $\mathrm{HCV}$ might be more prominent in Croatian population. In addition, it seems that

338 compared to Ge et al.'s cohort of chronically infected HCV patients (Ge et al. 2009), penetrance

339 of nonresponders in our IVDU cohort exhibited considerably lower value. This might indicate

340 that the genetic background of Croatian population is such that both the HCV spontaneous

341 clearance and the response to therapy in chronically infected IVDU is more pronounced in this

342 population. Having in mind that the population differences in rates of spontaneous clearance

343 have also been proposed for IVDU patients (Fischer et al. 2004; Miedzinski \& Taylor 2008), the

344 impact of IL-28B polymorphism on the spontaneous clearance of HCV in Croatian population

345 should be investigated in more details in order to increase our knowledge on the therapeutic

346 effectiveness of PegIFN- $\alpha 2 \mathrm{a} /$ ribavirin on rs12979860 genotypes in different populations,

347 particularly in high-HCV-risk IVDU population.

348

349 CONCLUSIONS

350 In conclusion, we have identified that the rs1800795-IL6 CC genotype is associated with

351 significantly better sustained virological response to the standard Peg IFN and ribavirin treatment

352 in IVDU/HCV patients. Also, findings point towards strong protective role of rs12979860-IL28B

353 CC genotype in acquiring chronic hepatitis $\mathrm{C}$ infection in Croatian IVDU population. Finally,

354 among all covariates, age is the most important, where every additional year slightly decreases

355 the chance of SVR response. Further prospective and large scale clinical studies are necessary to 356 confirm our results before we can prospectively identify IVDU and HCV patients for whom 357 therapy is likely to be successful.

358

359 ACKNOWLEDGEMENT: 
360 We thank our patients for taking part in this study, and Mrs. Sandra Vujević for technical

361 assistance.

362 REFERENCES:

363

364

365

366

367

368

369

370

371

372

373

374

375

376

377

378

379

380

381

382

383

384

385

386

387

388

389

390

391

392

393

394

395

396

397

398

399

Arslani N, Gajzer B, Papes D, Rajkovic Z, Altarac S, Zore Z, and Filipovic-Zore I. 2013. A new approach for transversalis fascia reinforcement in Lichtenstein's inguinal hernia repair. Surg Today 43:211-214. 10.1007/s00595-012-0232-7

Averhoff FM, Glass N, and Holtzman D. 2012. Global burden of hepatitis C: considerations for healthcare providers in the United States. Clin Infect Dis 55 Suppl 1:S10-15. $10.1093 / \mathrm{cid} / \mathrm{cis} 361$

Barrett S, Goh J, Coughlan B, Ryan E, Stewart S, Cockram A, O'Keane JC, and Crowe J. 2001. The natural course of hepatitis $\mathrm{C}$ virus infection after 22 years in a unique homogenous cohort: spontaneous viral clearance and chronic HCV infection. Gut 49:423-430.

Cavalcante LN, Abe-Sandes K, Angelo AL, Machado TM, Lemaire DC, Mendes CM, Pinho JR, Malta F, Lyra LG, and Lyra AC. 2012. IL28B polymorphisms are markers of therapy response and are influenced by genetic ancestry in chronic hepatitis $\mathrm{C}$ patients from an admixed population. Liver Int 32:476-486. 10.1111/j.1478-3231.2011.02653.x

Cussigh A, Falleti E, Fabris C, Bitetto D, Cmet S, Fontanini E, Bignulin S, Fornasiere E, Fumolo E, Minisini R, Pirisi M, and Toniutto P. 2011. Interleukin 6 promoter polymorphisms influence the outcome of chronic hepatitis C. Immunogenetics 63:33-41. 10.1007/s00251010-0491-7

Donnelly RP, and Kotenko SV. 2010. Interferon-lambda: a new addition to an old family. $J$ Interferon Cytokine Res 30:555-564. 10.1089/jir.2010.0078

Duggal P, Thio CL, Wojcik GL, Goedert JJ, Mangia A, Latanich R, Kim AY, Lauer GM, Chung RT, Peters MG, Kirk GD, Mehta SH, Cox AL, Khakoo SI, Alric L, Cramp ME, Donfield SM, Edlin BR, Tobler LH, Busch MP, Alexander G, Rosen HR, Gao X, Abdel-Hamid M, Apps R, Carrington M, and Thomas DL. 2013. Genome-wide association study of spontaneous resolution of hepatitis $\mathrm{C}$ virus infection: data from multiple cohorts. Ann Intern Med 158:235-245. 10.7326/0003-4819-158-4-201302190-00003

European Association for the Study of the Liver E. 2014. EASL Clinical Practice Guidelines: management of hepatitis C virus infection. J Hepatol 60:392-420. 10.1016/j.jhep.2013.11.003

Ezzikouri S, Alaoui R, Rebbani K, Brahim I, Fakhir FZ, Nadir S, Diepolder H, Khakoo SI, Thursz M, and Benjelloun S. 2013. Genetic variation in the interleukin-28B gene is associated with spontaneous clearance and progression of hepatitis $\mathrm{C}$ virus in Moroccan patients. PLoS One 8:e54793. 10.1371/journal.pone.0054793

Falleti E, Fabris C, Vandelli C, Colletta C, Cussigh A, Smirne C, Fontanini E, Cmet S, Minisini R, Bitetto D, Toniutto P, and Pirisi M. 2010. Genetic polymorphisms of interleukin-6 modulate fibrosis progression in mild chronic hepatitis C. Hum Immunol 71:999-1004. 10.1016/j.humimm.2010.06.006 
400

401

402

403

404

405

406

407

408

409

410

411

412

413

414

415

416

417

418

419

420

421

422

423

424

425

426

427

428

429

430

431

432

433

434

435

436

437

438

439

440

441

442

443

444
Fischer B, Haydon E, Rehm J, Krajden M, and Reimer J. 2004. Injection drug use and the hepatitis $\mathrm{C}$ virus: considerations for a targeted treatment approach--the case study of Canada. J Urban Health 81:428-447. 10.1093/jurban/jth128

Fishman D, Faulds G, Jeffery R, Mohamed-Ali V, Yudkin JS, Humphries S, and Woo P. 1998. The effect of novel polymorphisms in the interleukin-6 (IL-6) gene on IL-6 transcription and plasma IL-6 levels, and an association with systemic-onset juvenile chronic arthritis. J Clin Invest 102:1369-1376. 10.1172/JCI2629

Fox BA, Sheppard PO, and O'Hara PJ. 2009. The role of genomic data in the discovery, annotation and evolutionary interpretation of the interferon-lambda family. PLoS One 4:e4933. 10.1371/journal.pone.0004933

Ge D, Fellay J, Thompson AJ, Simon JS, Shianna KV, Urban TJ, Heinzen EL, Qiu P, Bertelsen AH, Muir AJ, Sulkowski M, McHutchison JG, and Goldstein DB. 2009. Genetic variation in IL28B predicts hepatitis C treatment-induced viral clearance. Nature 461:399-401. 10.1038/nature08309

Gelinas JF, Fabre T, Willems P, Leung RC, George J, Willems B, Bruneau J, and Shoukry NH. 2013. IL28B SNP screening and distribution in the French Canadian population using a rapid PCR-based test. Immunogenetics 65:397-403. 10.1007/s00251-013-0688-7

Ghany MG, Strader DB, Thomas DL, and Seeff LB. 2009. Diagnosis, management, and treatment of hepatitis C: an update. Hepatology 49:1335-1374. 10.1002/hep.22759

Grivennikov S, Karin E, Terzic J, Mucida D, Yu GY, Vallabhapurapu S, Scheller J, Rose-John S, Cheroutre H, Eckmann L, and Karin M. 2009. IL-6 and Stat3 are required for survival of intestinal epithelial cells and development of colitis-associated cancer. Cancer Cell 15:103-113. 10.1016/j.ccr.2009.01.001

Halfon P, Bourliere M, Ouzan D, Maor Y, Renou C, Wartelle C, Penaranda G, Tran A, Botta D, Oules V, Castellani P, Portal I, Argiro L, and Dessein A. 2011. A single IL28B genotype SNP rs12979860 determination predicts treatment response in patients with chronic hepatitis C Genotype 1 virus. European Journal of Gastroenterology \& Hepatology 23:931-935. 10.1097/MEG.0b013e328349d0ef

Harrington LE, Hatton RD, Mangan PR, Turner H, Murphy TL, Murphy KM, and Weaver CT. 2005. Interleukin 17-producing CD4+ effector T cells develop via a lineage distinct from the T helper type 1 and 2 lineages. Nat Immunol 6:1123-1132. 10.1038/ni1254

Ishak K, Baptista A, Bianchi L, Callea F, De Groote J, Gudat F, Denk H, Desmet V, Korb G, MacSween RN, Phillips MJ, Portmann BG, Poulsen H, Scheuer PJ, Schmid M, and Thaler H. 1995. Histological grading and staging of chronic hepatitis. J Hepatol 22:696699.

Knodell RG, Ishak KG, Black WC, Chen TS, Craig R, Kaplowitz N, Kiernan TW, and Wollman J. 1981. Formulation and application of a numerical scoring system for assessing histological activity in asymptomatic chronic active hepatitis. Hepatology 1:431-435.

Kopf M, Baumann H, Freer G, Freudenberg M, Lamers M, Kishimoto T, Zinkernagel R, Bluethmann H, and Kohler G. 1994. Impaired immune and acute-phase responses in interleukin-6-deficient mice. Nature 368:339-342. 10.1038/368339a0

Kurbanov F, Abdel-Hamid M, Latanich R, Astemborski J, Mohamed M, Mikhail NMH, El-Daly M, El-Kafrawy S, Thomas DL, and Thio CL. 2011. Genetic Polymorphism in IL28B Is Associated With Spontaneous Clearance of Hepatitis C Virus Genotype 4 Infection in an Egyptian Cohort. Journal of Infectious Diseases 204:1391-1394. 10.1093/infdis/jir536 
445

446

447

448

449

450

451

452

453

454

455

456

457

458

459

460

461

462

463

464

465

466

467

468

469

470

471

472

473

474

475

476

477

478

479

480

481

482

483

484

485

486

487

488

489

490

Lapinski TW. 2001. The levels of IL-1beta, IL-4 and IL-6 in the serum and the liver tissue of chronic HCV-infected patients. Arch Immunol Ther Exp (Warsz) 49:311-316.

Lewis CM, and Knight J. 2012. Introduction to genetic association studies. Cold Spring Harb Protoc 2012:297-306. 10.1101/pdb.top068163

Li M, and Huang D. 2007. On-column refolding purification and characterization of recombinant human interferon-lambdal produced in Escherichia coli. Protein Expr Purif 53:119-123. 10.1016/j.pep.2006.11.011

Lin CY, Chen JY, Lin TN, Jeng WJ, Huang CH, Huang CW, Chang SW, and Sheen IS. 2011. IL28B SNP rs 12979860 Is a Critical Predictor for On-Treatment and Sustained Virologic Response in Patients with Hepatitis C Virus Genotype-1 Infection. PLoS One 6. ARTN e18322

10.1371/journal.pone.0018322

Lindh M, Lagging M, Farkkila M, Langeland N, Morch K, Nilsson S, Norkrans G, Pedersen C, Buhl MR, Westin J, and Hellstrand K. 2011. Interleukin 28B Gene Variation at rs 12979860 Determines Early Viral Kinetics During Treatment in Patients Carrying Genotypes 2 or 3 of Hepatitis C Virus. Journal of Infectious Diseases 203:1748-1752. 10.1093/infdis/jir193

Luo YQ, Jin CX, Ling ZX, Mou XZ, Zhang Q, and Xiang C. 2013. Association study of IL28B: rs 12979860 and rs8099917 polymorphisms with SVR in patients infected with chronic HCV genotype 1 to PEG-INF/RBV therapy using systematic meta-analysis. Gene 513:292-+. 10.1016/j.gene.2012.10.030

Malaguarnera M, Di Fazio I, Romeo MA, Restuccia S, Laurino A, and Trovato BA. 1997. Elevation of interleukin 6 levels in patients with chronic hepatitis due to hepatitis $\mathrm{C}$ virus. J Gastroenterol 32:211-215.

Miedzinski L, and Taylor G. 2008. Ethnicity and spontaneous clearance of hepatitis C in HIVHCV coinfected patients. Can J Infect Dis Med Microbiol 19:316.

Montes-Cano MA, Garcia-Lozano JR, Abad-Molina C, Romero-Gomez M, Barroso N, AguilarReina J, Nunez-Roldan A, and Gonzalez-Escribano MF. 2010. Interleukin-28B genetic variants and hepatitis virus infection by different viral genotypes. Hepatology 52:33-37. 10.1002/hep. 23624

Muir AJ, Shiffman ML, Zaman A, Yoffe B, de la Torre A, Flamm S, Gordon SC, Marotta P, Vierling JM, Lopez-Talavera JC, Byrnes-Blake K, Fontana D, Freeman J, Gray T, Hausman D, Hunder NN, and Lawitz E. 2010. Phase 1b study of pegylated interferon lambda 1 with or without ribavirin in patients with chronic genotype 1 hepatitis $\mathrm{C}$ virus infection. Hepatology 52:822-832. 10.1002/hep.23743

Muraguchi A, Hirano T, Tang B, Matsuda T, Horii Y, Nakajima K, and Kishimoto T. 1988. The essential role of B cell stimulatory factor 2 (BSF-2/IL-6) for the terminal differentiation of B cells. $J$ Exp Med 167:332-344.

Nattermann J, Timm J, Nischalke HD, Olbrich A, Michalk M, Tillmann HL, Berg T, Wedemeyer H, Tenckhoff H, Wiese M, Kullig U, Gobel U, Capka E, Schiefke I, Guthof W, Grungreiff K, Konig I, Roggendorf M, Sauerbruch T, and Spengler U. 2011. The predictive value of IL28B gene polymorphism for spontaneous clearance in a single source outbreak cohort is limited in patients carrying the CCR5Delta32 mutation. $J$ Hepatol 55:1201-1206. 10.1016/j.jhep.2011.03.011

Nattermann J, Vogel M, Berg T, Danta M, Axel B, Mayr C, Bruno R, Tural C, Klausen G, Clotet B, Lutz T, Grunhage F, Rausch M, Nischalke HD, Schewe K, Bienek B, Haerter G, 
491

492

493

494

495

496

497

498

499

500

501

502

503

504

505

506

507

508

509

510

511

512

513

514

515

516

517

518

519

520

521

522

523

524

525

526

527

528

529

530

531

532

533

534

535

Sauerbruch T, Rockstroh JK, and Spengler U. 2007. Effect of the interleukin-6 C174G gene polymorphism on treatment of acute and chronic hepatitis $\mathrm{C}$ in human immunodeficiency virus coinfected patients. Hepatology 46:1016-1025. 10.1002/hep. 21778

Pagliaccetti NE, and Robek MD. 2010. Interferon-lambda in HCV Infection and Therapy. Viruses 2:1589-1602. 10.3390/v2081589

Polasek O. 2013. Future of biobanks - bigger, longer, and more dimensional. Croat Med J 54:496-500.

Purcell S, Neale B, Todd-Brown K, Thomas L, Ferreira MA, Bender D, Maller J, Sklar P, de Bakker PI, Daly MJ, and Sham PC. 2007. PLINK: a tool set for whole-genome association and population-based linkage analyses. Am J Hum Genet 81:559-575. $10.1086 / 519795$

Rudan I, Marusic A, Jankovic S, Rotim K, Boban M, Lauc G, Grkovic I, Dogas Z, Zemunik T, Vatavuk Z, Bencic G, Rudan D, Mulic R, Krzelj V, Terzic J, Stojanovic D, Puntaric D, Bilic E, Ropac D, Vorko-Jovic A, Znaor A, Stevanovic R, Biloglav Z, and Polasek O. 2009. "10001 Dalmatians:" Croatia launches its national biobank. Croat Med J 50:4-6.

Seaberg EC, Witt MD, Jacobson LP, Detels R, Rinaldo CR, Margolick JB, Young S, Phair JP, and Thio CL. 2015. Spontaneous Clearance of the Hepatitis C Virus Among Men Who Have Sex With Men. Clin Infect Dis 61:1381-1388. 10.1093/cid/civ562

Shi XD, Pan Y, Wang ML, Wang DS, Li WY, Jiang T, Zhang P, Chi XM, Jiang YF, Gao YH, Zhong J, Sun B, Xu DM, Jiang J, and Niu JQ. 2012. IL28B Genetic Variation Is Associated with Spontaneous Clearance of Hepatitis C Virus, Treatment Response, Serum IL-28B Levels in Chinese Population. PLoS One 7. ARTN e37054

10.1371/journal.pone.0037054

Suppiah V, Moldovan M, Ahlenstiel G, Berg T, Weltman M, Abate ML, Bassendine M, Spengler U, Dore GJ, Powell E, Riordan S, Sheridan D, Smedile A, Fragomeli V, Muller T, Bahlo M, Stewart GJ, Booth DR, and George J. 2009. IL28B is associated with response to chronic hepatitis $\mathrm{C}$ interferon-alpha and ribavirin therapy. Nat Genet 41:1100-1104. 10.1038/ng.447

Tanaka Y, Nishida N, Sugiyama M, Kurosaki M, Matsuura K, Sakamoto N, Nakagawa M, Korenaga M, Hino K, Hige S, Ito Y, Mita E, Tanaka E, Mochida S, Murawaki Y, Honda M, Sakai A, Hiasa Y, Nishiguchi S, Koike A, Sakaida I, Imamura M, Ito K, Yano K, Masaki N, Sugauchi F, Izumi N, Tokunaga K, and Mizokami M. 2009. Genome-wide association of IL28B with response to pegylated interferon-alpha and ribavirin therapy for chronic hepatitis C. Nat Genet 41:1105-1109. 10.1038/ng.449

Thomas DL, Thio CL, Martin MP, Qi Y, Ge D, O'Huigin C, Kidd J, Kidd K, Khakoo SI, Alexander G, Goedert JJ, Kirk GD, Donfield SM, Rosen HR, Tobler LH, Busch MP, McHutchison JG, Goldstein DB, and Carrington M. 2009. Genetic variation in IL28B and spontaneous clearance of hepatitis C virus. Nature 461:798-801. 10.1038/nature08463

Tillmann HL, Thompson AJ, Patel K, Wiese M, Tenckhoff H, Nischalke HD, Lokhnygina Y, Kullig U, Gobel U, Capka E, Wiegand J, Schiefke I, Guthoff W, Grunfreiff K, Konig I, Spengler U, McCarthy J, Shianna KV, Goldstein DB, McHutchison JG, Timm J, Nattermann J, and Grp GA-DS. 2010. A Polymorphism Near IL28B Is Associated With Spontaneous Clearance of Acute Hepatitis C Virus and Jaundice. Gastroenterology 139:1586-+. 10.1053/j.gastro.2010.07.005 
536 WHO. 2014. Guidelines for the screening, care and treatment of persons with Hepatitis C

537

538

539

540

541

542

543

544

545

546

547

548

549

550

551

552 infection. Available at http://apps.who.int/iris/bitstream/10665/111747/1/9789241548755 eng.pdf?ua=1andua $=1$ (accessed Sep 01 2016).

Wilson AG, Symons JA, McDowell TL, McDevitt HO, and Duff GW. 1997. Effects of a polymorphism in the human tumor necrosis factor alpha promoter on transcriptional activation. Proc Natl Acad Sci U S A 94:3195-3199.

Wittke-Thompson JK, Pluzhnikov A, and Cox NJ. 2005. Rational inferences about departures from Hardy-Weinberg equilibrium. Am J Hum Genet 76:967-986. 10.1086/430507

Zeuzem S, Andreone P, Pol S, Lawitz E, Diago M, Roberts S, Focaccia R, Younossi Z, Foster GR, Horban A, Ferenci P, Nevens F, Mullhaupt B, Pockros P, Terg R, Shouval D, van Hoek B, Weiland O, Van Heeswijk R, De Meyer S, Luo D, Boogaerts G, Polo R, Picchio G, and Beumont M. 2011. Telaprevir for retreatment of HCV infection. $N$ Engl J Med 364:2417-2428. 10.1056/NEJMoa1013086 
553 Table 1. Demographic and clinical characteristics of IVDU patients by the response-to554 treatment status

555

\begin{tabular}{|c|c|c|c|}
\hline & SVR, $N=78$ & $N R, N=32$ & Statistics \\
\hline \multicolumn{4}{|l|}{ Sex, N (\%) } \\
\hline men & $56(72 \%)$ & $26(81 \%)$ & \multirow{2}{*}{ Chi square test, $p=0.301$} \\
\hline women & $22(28 \%)$ & $6(19 \%)$ & \\
\hline Age, median (IQR) & $40(35-45)$ & $41.5(39-47)$ & Mann-Whitney, $\mathrm{p}=0.041$ \\
\hline \multicolumn{4}{|l|}{ Fibrosis stage, $N(\%)$} \\
\hline Mean Ishak score $\dagger$ & $3(2.0-3.0)$ & $2(1.0-3.0)$ & Mann-Whitney, $\mathrm{p}=0.077$ \\
\hline Mean Knodell score & $7(5.0-9.0)$ & $6(5.0-9.0)$ & Mann-Whitney, $\mathrm{p}=0.803$ \\
\hline \multicolumn{4}{|l|}{ Viral genotype, $\mathbf{N}(\%)$} \\
\hline 1 & $51(73 \%)$ & $19(27 \%)$ & \multirow{2}{*}{ Chi square test $\mathrm{P}=0.706$} \\
\hline 3 & $27(68 \%)$ & $13(33 \%)$ & \\
\hline
\end{tabular}

556 SVR-sustained viral response; NR-non responders

$557 \uparrow$ Liver fibrosis was scored by Ishak fibrosis score (0-6) as previously described. (Ishak et al. 1995)10

$558 \$$ Histology activity index by Knodell score (0-18) in chronic active hepatitis. (Knodell et al. 1981)9 
559 Table 2. Distributions of rs1800795- IL6 and rs12979860- IL28B genotypes, by the 560 response-to-treatment group

561

\begin{tabular}{|c|c|c|c|c|}
\hline \multirow[t]{2}{*}{ SNP } & Genotype & SVR, $N=78$ & $\mathrm{NR}, \mathrm{N}=32$ & Total \\
\hline & $\mathrm{CC}$ & $22(28 \%)$ & $8(25 \%)$ & $30(27 \%)$ \\
\hline \multirow[t]{2}{*}{ IL-28B, N (\%) } & CT & $50(64 \%)$ & $19(59 \%)$ & $69(63 \%)$ \\
\hline & TT & $6(8 \%)$ & $5(16 \%)$ & $11(10 \%)$ \\
\hline \multirow{3}{*}{ IL-6, N (\%) } & GG & $27(35 \%)$ & $16(50 \%)$ & $43(39 \%)$ \\
\hline & GC & $37(47 \%)$ & $15(47 \%)$ & $52(47 \%)$ \\
\hline & $\mathrm{CC}$ & $14(18 \%)$ & $1(3 \%)$ & $15(14 \%)$ \\
\hline
\end{tabular}

562 SVR-sustained viral response; NR-non responders 


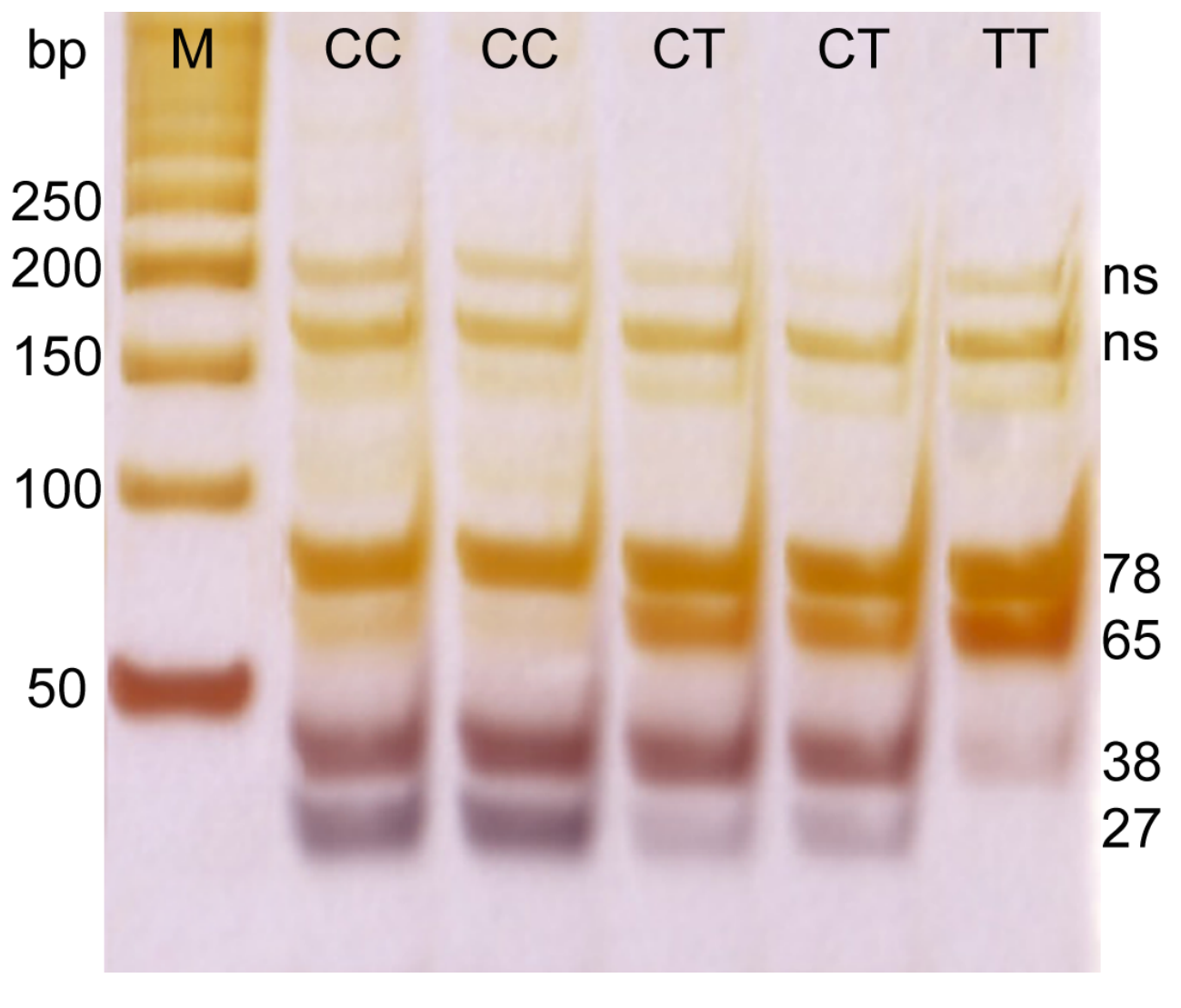

565 Figure 1. PCR electrophoresis results for rs 12979860 genotyping.

566 M-marker; ns-non specific band; CC, CT, and TT - rs12979860 genotypes

567

568

569

570

571

572

573

574

575

576

577

578

579

580

581

582

583

584 


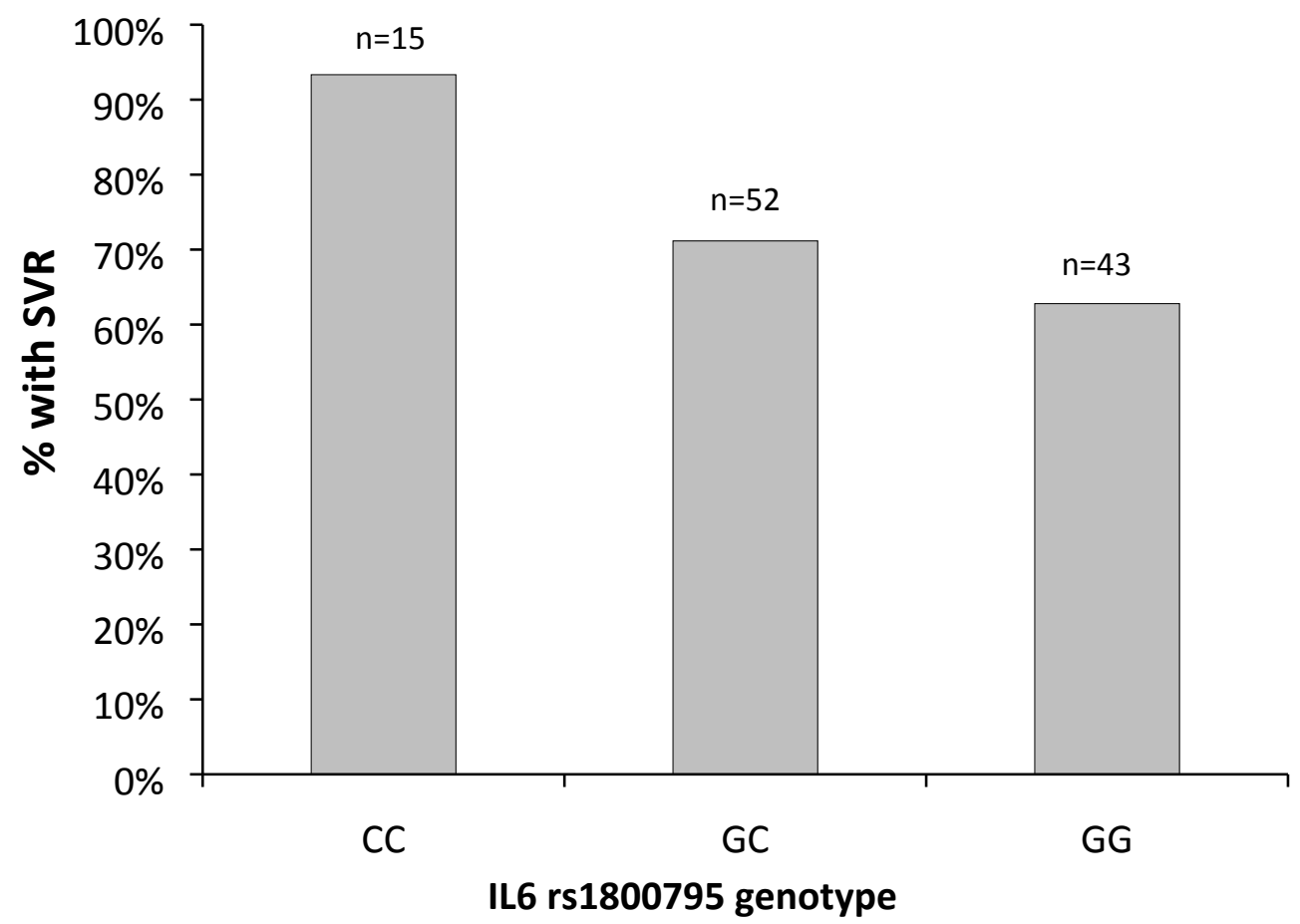

585

586 Figure 2. The percentage of patients with SVR by the rs1800795-IL6 genotypes.

$587 \mathrm{n}=$ total number of patients with each genotype.

588

589

590 


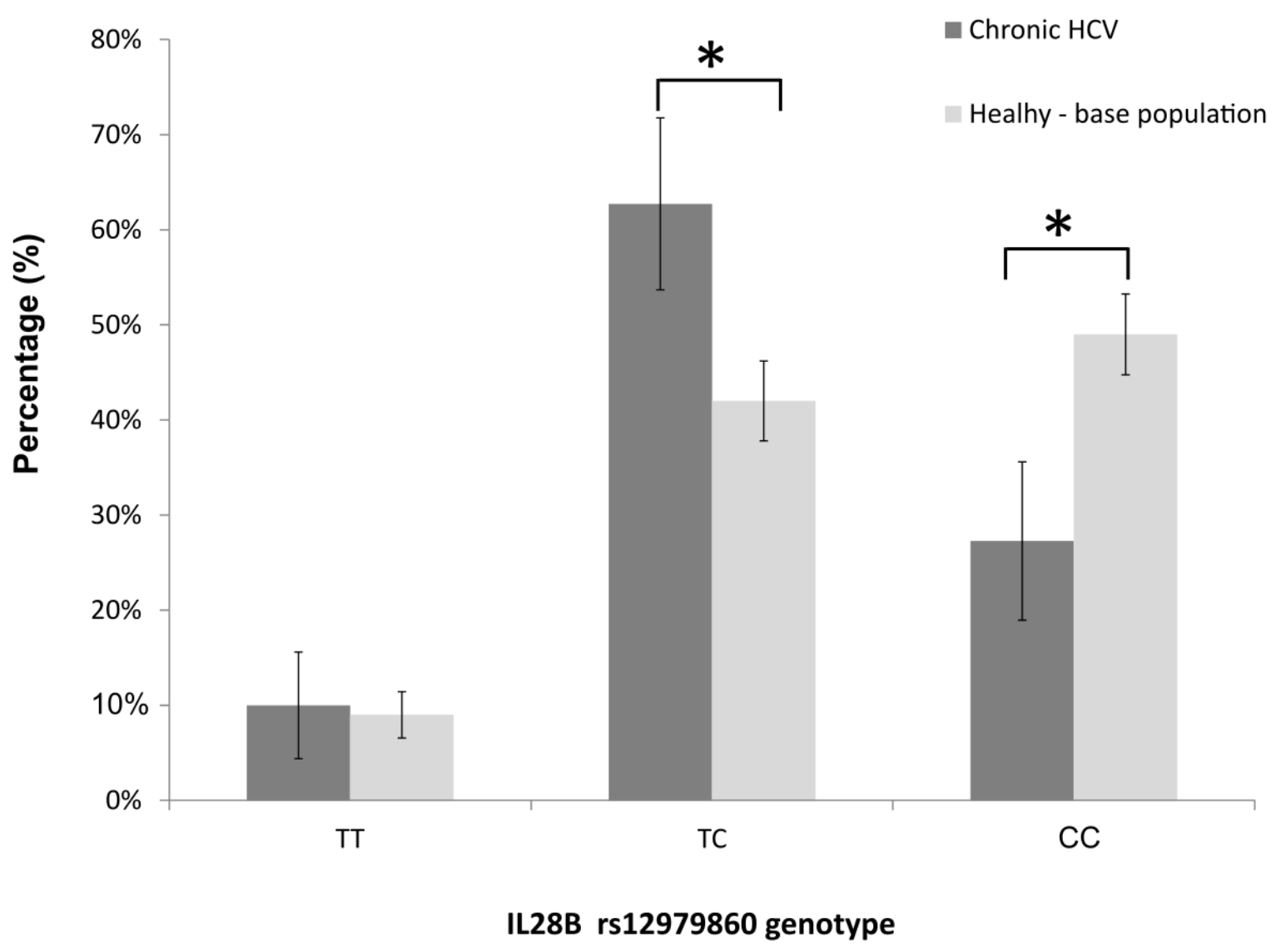

591

592 Figure 3. The distribution of rs12979860-IL28B genotypes among: IVDU with chronic HCV (in

593 black bars), and the underlying (base), apparently healthy population (in gray bars). Shown are

594 percentages with accompanying 95\% CI.

$595 *$ Statistically significant difference, $\mathrm{P}<0.05$ 